\title{
Crónicas sobre las Jornadas sobre La ordenación de la energía (Sevilla y Málaga, noviembre de 2011)
}

\author{
Roberto Galán Vioque \\ Profesor Titular de Derecho Administrativo \\ Universidad de Sevilla \\ Elsa Marina Álvarez González
}

Profesora Ayudante Doctora

Universidad de Málaga

Los días 18 y 24 y 25 de noviembre de 2011 se han desarrollado en las Universidades de Sevilla y Málaga, respectivamente, unas Jornadas que han tenido como objeto la Ordenación de la energía. Estas Jornadas, que contaron con un gran éxito de público, fueron organizadas por el Instituto Universitario de Investigación García Oviedo de la Universidad de Sevilla en el marco del Proyecto de Excelencia Andalucia Tech. Su dirección corrió a cargo de los Catedráticos de Derecho Administrativo de Sevilla y Málaga, respectivamente, los Profesores Alfonso Pérez Moreno y Diego Vera Jurado. Contaron con la participación de expertos en Derecho de la energía y representantes tanto de la Administración energética española como del sector empresarial de la energía. Las Jornadas propiciaron el encuentro entre todos estos agentes tan decisivos para la ordenación de la energía.

Jornada del día 18 de noviembre de 2011 en Sevilla

La inauguración de las Jornadas corrió a cargo de la Presidenta de la Agencia Andaluza de la Energía, Isabel de Haro Aramberri, que hizo una síntesis de la situación energética en Andalucía, haciendo especial hincapié en el esfuerzo que se ha hecho en relación con el fomento de las energías renovables. Lo que ha situado a la Comunidad Autónoma de Andalucía en una posición de liderazgo dentro de nuestro país en este sector.

A continuación el Profesor Alfonso Pérez Moreno hizo un análisis del régimen jurídico del sector eléctrico, que ha sido objeto de importantes modifi- 
caciones en los últimos tiempos, centrándose en la composición del llamado mix energético, es decir, las distintas fuentes de producción primaria de energía eléctrica. Se hizo eco de la reciente aprobación por parte del Gobierno de la planificación energética indicativa que era un mandato establecido en la Ley de Economía sostenible, concluyendo en la necesidad de apostar por las energías renovables como vía para diversificar las fuentes de producción eléctrica, mitigar nuestra dependencia energética del petróleo y luchar contra el cambio climático. La segunda ponencia la asumió el Profesor Christian Pielow, Profesor de Derecho Público de la Universidad de Bochum y uno de los mayores expertos europeos en Derecho de la energía, quien se centró en analizar el desarrollo, motorizado, que ha tenido la legislación comunitaria en materia energética, con la finalidad clara de liberalizar este sector a nivel europeo para conseguir mayor competitividad de las empresas eléctricas europeas.

La mañana concluyó con una interesante mesa redonda que versó sobre el papel neurálgico que las redes de electricidad tienen en relación con la producción eléctrica. José Domínguez Abascal, Secretario General Técnico de Abengoa, destacó la importancia que tiene para España contar con un sector tecnológico puntero a nivel mundial en el terreno de las energías renovables y del riesgo que supondría poner restricciones a su expansión. Por su parte, Mariano Bacigalupo Segasse, Profesor Titular de Derecho Administrativo de la Universidad Nacional de Educación a Distancia y Secretario de la Comisión Nacional de la Energía prestó especial atención a la complejidad administrativa del reconocimiento del derecho de acceso a las redes eléctricas por parte de los productores de energía y, en particular, para los productores de energías renovables. Ricardo Pérez Blanco, Jefe de la Asesoría Jurídica de ENDESA, habló sobre la función que las empresas de distribución eléctrica tienen a la hora de transportar la electricidad, compatibilizando el acceso a las energías renovables con la garantía del suministro eléctrico. El Profesor Titular de Derecho Administrativo de la Universidad de Sevilla Antonio J. Sánchez Sáez destacó las disfunciones derivadas de la naturaleza oligopolística que tiene el sector eléctrico en el acceso a las redes. Por último Suzana Tavares da Silva, Profesora de la Facultad de Derecho de Coimbra y colaboradora del Centro de Estudos de Direito do Ordenamento de esta misma ciudad lusa hizo referencia a la situación del denominado mercado ibérico de la electricidad poniendo de relieve las dificultades que los productores de energías renovables tienen en Portugal para poder acceder a las redes de electricidad.

Las Jornadas sobre la Ordenación de la energía continuaron por la tarde con la intervención del Profesor Titular de Derecho Administrativo, Roberto Galán Vioque que abordó la evolución del modelo español de fomento de las 
energías renovables, que ha convertido a nuestro país en uno de los países líderes mundiales en energías renovables. Se detuvo, especialmente, en los últimos cambios que se han introducido en el régimen jurídico del fomento de las energías renovables que, en el contexto de la actual crisis económica, han estado orientados a una reducción del coste económico del apoyo a las energías renovables. Lo que ha sembrado de preocupación a todo el sector. A continuación el Profesor Antonio Jiménez-Blanco Carrillo de Albornoz, Catedrático de Derecho Administrativo de la Universidad Politécnica de Madrid, reflexionó sobre la aplicación de la prohibición constitucional de la irretroactividad de las disposiciones restrictivas de derechos individuales al recorte introducidos en el régimen económico de fomento de las energías renovables, en particular, en relación con la energía solar fotovoltaica.

Las jornadas en Sevilla se cerraron con una mesa redonda que moderó el Catedrático de Derecho Administrativo Francisco López Menudo y que tuvo como objeto el control sobre la legislación de fomento de las energías renovables. En esta mesa intervinieron Estanislao Arana García, Catedrático de Derecho Administrativo de la Universidad de Granada, Rafael Fernández Valverde, Magistrado de la Sala de lo contencioso-administrativo del Tribunal Supremo y Valeriano Ruiz, Catedrático de Máquinas y Motores de la Universidad de Sevilla quienes desde sus distintas perspectivas analizaron las dificultades de control que existe en relación con la normativa española de fomento de las energías renovables.

\section{Jornadas de los días 24 y 25 de noviembre de 2011 en Málaga}

La celebración de estas Jornadas sobre la ordenación de la energía en su sede malagueña durante los días 24 y 25 de noviembre de 2011, se caracterizó por la participación de un nutrido grupo de expertos en Derecho administrativo, abogados especialistas en la materia, así como ingenieros técnicos con demostrada valía en el ámbito energético. Este carácter interdisciplinar consiguió transmitir al público asistente importantes ideas y reflexiones sobre la situación actual de la regulación jurídica de la energía.

La estructura que se siguió respondía a un objetivo doble: en primer lugar, exponer en diferentes sesiones el régimen jurídico de la energía a través de ponencias plenarias que corrieron a cargo del Profesor Ángel Menéndez Rexach, Catedrático de Derecho Administrativo de la Universidad Autónoma de Madrid; la Profesora Blanca Lozano Cutanda, Catedrática de Derecho Administrativo de la Universidad del País Vasco y el Profesor Tomás de la Quadra Salcedo, Catedrático de Derecho Administrativo de la Universidad Carlos III; y 
en segundo término, introducir a continuación de cada ponencia una mesa redonda donde los participantes pudieran reflexionar sobre las cuestiones más relevantes de la energía ante la ordenación del territorio; la energía ante el medio ambiente y el futuro de la energía.

En efecto, la incorporación de la variable ambiental en el proceso de toma de decisiones por las Administraciones Públicas podemos afirmar que es un logro ya consolidado. Sin embargo, parece necesario aún introducir nuevos esquemas en la ordenación territorial, en los que la apuesta por criterios de inversión en el sector energético se convierte en fundamental en estos momentos. Por ello, la planificación del desarrollo de la energía debe ser entendida como una herramienta básica para la ordenación de los recursos en materia energética, teniendo presente que las directrices de la política energética estatal suelen responder a macroobjetivos nacionales de consecución a largo plazo, los cuales muchas veces parecen contradictorios con los intereses regionales y locales y con su consecución a corto plazo, por lo que deberían articularse los mecanismos necesarios para la integración de todos los intereses en juego en los instrumentos de planificación.

Los profesionales y expertos reunidos en estas jornadas incidieron en la necesidad de rescatar un enfoque integral y multisectorial en la materia sobre los que diseñar propuestas de acción y de gestión en materia de energía. Así, por ejemplo, las nuevas soluciones proponen la adopción de un enfoque integral en la planificación de las energías renovables que englobe junto a las distintas alternativas físicas de captación y explotación de los recursos energéticos renovables, determinaciones de carácter tanto jurídico-administrativo, económico-financiero como social.

Además, resulta indispensable en estos momentos que la planificación energética no sólo sirva de garante de las inversiones del sector público, sino que avance en la participación del sector privado en los proyectos de desarrollo de estas energías, pues el sector privado necesita un marco definido y unas reglas claras, sobre todo en cuanto a sistemas de precios y calendario de inversiones del sector público. Como es obvio, la falta de reglas claras desincentiva la intervención del sector privado, lo que se agrava aún más en situaciones de crisis económica donde los recortes presupuestos afecta de forma directa no sólo a las inversiones públicas sino también a las ayudas públicas en la materia.

Por otro lado, el régimen jurídico del sector energético se encuentra todavía a día de hoy a caballo entre el servicio público y la liberación. En efecto, el proceso normativo que ha afectado a este sector desde 1997 ha implicado cam- 
bios profundos en la organización y regulación del sector, siendo, sin duda, el más característico la propia liberalización del sector y la introducción de la competencia, que, sin embargo, aún no se ha conseguido implantar de forma real. Esto nos lleva a la necesidad de reflexionar sobre el papel que debe adoptar la Administración pública en los servicios de interés económico general liberalizados como la energía, máxime cuando el proceso liberalizador ha ido acompañado de una privatización de la actividad como en el caso del sector eléctrico y del gas.

En consecuencia, el nuevo modelo regulatorio establecido para este sector de la actividad está necesitado de una profunda revisión en la que quizás debemos volver a recoger algunos postulados del viejo modelo de servicio público como son los objetivos de interés general, la seguridad del suministro la solidaridad social e interterritorial, así como el derecho de acceso de todos a la prestación de los servicios de interés general. Sólo así, podremos encontrar respuesta a los problemas actuales de falta de competencia real en el mercado energético o de déficit tarifario.

El marco jurídico del sector eléctrico es actualmente europeo. Ha sido la Unión Europea la que, como ha hecho en otros sectores, ha impulsado una fuerte liberalización del mercado eléctrico. Aunque los avances en el terreno de la competitividad han sido hasta ahora bastante modestos. No se pueden entender la situación del mercado eléctrico español o ibérico sin tener en cuenta la perspectiva del Derecho comunitario.

Nadie discute la importancia que en la producción eléctrica tienen las energías renovables. Es cierto que en España se ha hecho un gran esfuerzo inversor en este sector que ha dado unos resultados destacados. Pero este ritmo inversor, en el contexto actual de grave crisis económica y presupuestaria, es sencillamente insostenible. Urge un cambio normativo que permita seguir apostando por las energías renovables en España, que son el futuro de la energía, sin que suponga una pesada carga para los presupuestos públicos.

Probablemente una conclusión global de estas Jornadas sobre Ordenación de la Energía sea la necesidad de dotarse de un marco jurídico estable del mercado eléctrico que genere seguridad jurídica, donde desgraciadamente no la hay, para permitir un desarrollo equilibrado del sector eléctrico tanto en España como en el conjunto de Europa. 